\title{
Early Experience with Laparoscopic Surgery for Undescended Testis at a Tertiary Hospital in Ibadan (2015-2019)
}

\author{
Augustine O. Takure, Ijeoma J. Chibuzo, Oludolapo O. Afuwape, and Sikiru A. Adebayo
}

\section{ABSTRACT}

Background: Undescended testis (UDT) is of concern to the patient. If not treated may be complicated by trauma, torsion, male sub-fertility, and testicular cancer. In Nigeria it is commonly treated by open orchidopexy or orchidectomy. We report our experience with the laparoscopic management of undescended testes in the Western part of Nigeria.

\begin{abstract}
Methodology: The aim of this study was to report our early experience with the laparoscopic treatment of undescended testis in our centre. The study was conducted between January 2015 and December 2019. The data studied were age, unilateral or bilateral UDT, operation performed, preand intra-operative findings, operation time, and the outcome. The data were represented in tables and with operative pictures. Ethical clearance was obtained.

Results: A total 12 patients were treated which consisted of 7 children and 5 adults with a mean age of $11(6-17)$ years and $35.2(29-42)$ years respectively. Preoperatively, 9 patients had transperitoneal laparoscopic orchidopexy, orchidectomy or varicocelectomy. The laparoscopic findings were peeping testis (5), intraabdominal testis (8), intracanalicular (5), and one absent testis. All the post-orchidopexy testes remained in the scrotum at 18 months of follow up. In the adults, there was improvement in the semen parameters in 2 men while 3 had persistent azoospermia.
\end{abstract}

Conclusion: In our setting, laparoscopy for undescended testis is feasible, safe, diagnostic, and therapeutic. In infertile men with undescended testis and unilateral varicocele, laparoscopic varicocelectomy results in improved semen quality.

Keywords: laparoscopic varicocelectomy, laparoscopy, outcome, undescended testis.

\section{INTRODUCTION}

Undescended testis is the failure of the testis to descend into the bottom of the scrotum. The incidence of undescended testis varies with regions and age, it is $2.1 \%$ in Australia [1] and the prevalence is $0.82 \%$ in Nigeria [2]. At 1 year, it ranges from $1.0-1.5 \%$ while at 15 years it is $1.6-2.2 \%$ and it is rare after 15 years [3]. Undescended testis is also referred to as cryptorchidism which meant hidden testis. Some authors describe it as impalpable or non-palpable [2], [4]-[7]. The diagnosis is made on clinical examination. The testis can be localized in $21.3 \%$ and $33 \%$ by abdominal ultrasound, and $37.2 \%$ by magnetic resonance imaging (MRI) [5], [7], [8].

The diagnosis of undescended testis is confirmed at laparoscopy in all cases. Laparoscopy identifies the abdominal testes which could be high or low, peeping testes, canaliculi testes, blind ending cord structures, and vanishing testes [5]-[8]. These findings at laparoscopy determines the treatment options for undescended testis. These include single stage orchidopexy or orchidectomy. Or staged

\section{A. Study Site}

\section{B. Study Design}

Published Online: July 22, 2021

ISSN: $2736-5476$

DOI: $10.24018 /$ ejclinicmed.2021.2.3.95

\section{A. O. Takure*}

Department of Surgery, College of Medicine, University of Ibadan and University College Hospital, Ibadan, Nigeria.

(e-mail: augusturoendo@com)

\section{J. Chibuzo}

University of Ibadan and University College Hospital, Ibadan, Nigeria.

(e-mail: ijeomac2002@yahoo.com)

O. O. Afuwape

Department of Surgery, College of Medicine, University of Ibadan and University College Hospital, Ibadan, Nigeria.

(e-mail: dolafpe ${ }^{\circledR}$ yahoo.co.uk)

S. A. Adebayo

Department of Surgery, College of Medicine, University of Ibadan and University College Hospital, Ibadan, Nigeria.

(e-mail: sikobay@yahoo.com)

*Corresponding Author

orchidopexy (Fowler-Stephens technique) when the vessels of the cord structures are short and any attempt at one stage may compromise the testicular blood supply. [4]-[9].

Laparoscopy is rarely utilized in Nigeria in the treatment of undescended testes. However, majority of the cases are offered open orchidopexy or orchiectomy [10]-[13].

We describe our experience with laparoscopic treatment of undescended testes in children and adults in the division of urology in a tertiary hospital in Western part of Nigeria.

\section{MAteriALS AND MEthods}

University College Hospital in Ibadan, Nigeria.

Retrospective review of the data of children and adult patients with undescended testis who underwent laparoscopy between January 2015 and December 2019. 


\section{Figures Inclusion Criterium}

Patients with undescended testis not identified by clinical examination.

\section{Indices Studied}

The age, type of undescended testis either unilateral or bilateral, intraoperative findings at laparoscopic, types of procedure performed such as orchidopexy, orchidectomy or varicocelectomy and the operation time. The preoperative and postoperative semen parameters. The outcome of laparoscopy such testis in the scrotum or retracted and the quality of semen parameters.

\section{E. Laparoscopic Technique}

All patients had general anesthesia with appropriate endotracheal intubation. The carbondioxide pneumoperitoneum was created using a Verres needle and the intraabdominal insufflation pressure was $8-12 \mathrm{~mm}$ and 15$18 \mathrm{~mm}$ for children and adults. The primary trocar port was $10 \mathrm{~mm}$ while two secondary ports of $5 \mathrm{~mm}$ each were introduced at midpoint of ilio-umbilical line (Fig. 1).

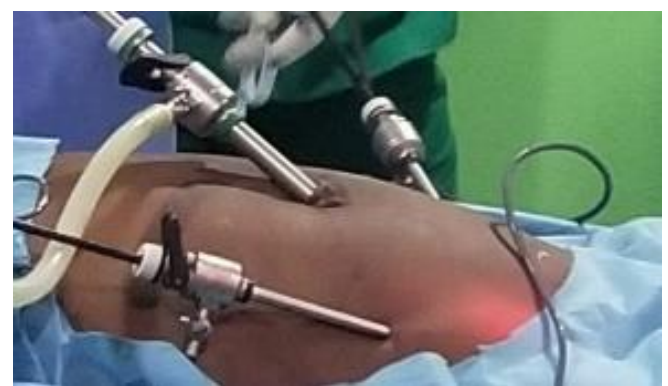

Fig. 1. Ports for laparoscopic orchidopexy or orchidectomy.

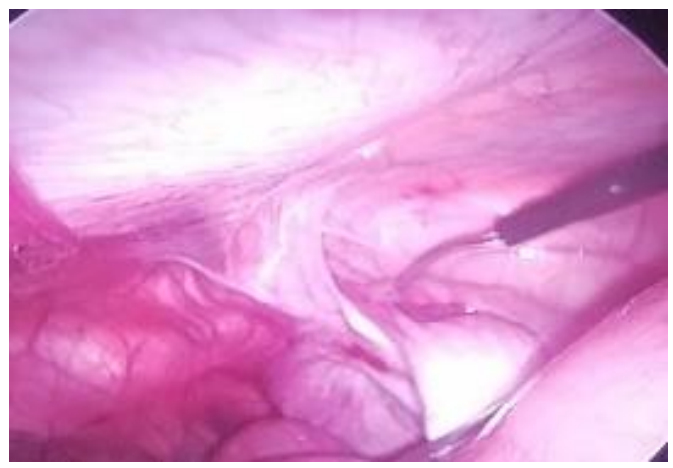

Fig. 2. Right intraabdominal testis.

The laparoscopic location of presence or absence of the testes were noted (Fig. 2, 3, and 4).

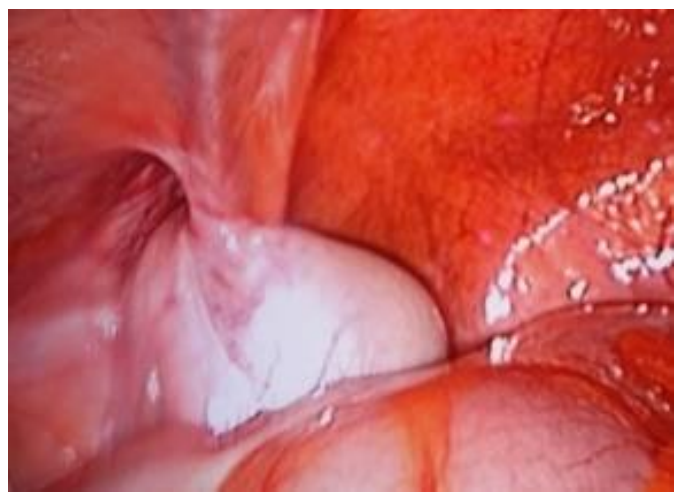

Fig. 3. Left intraabdominal testis.

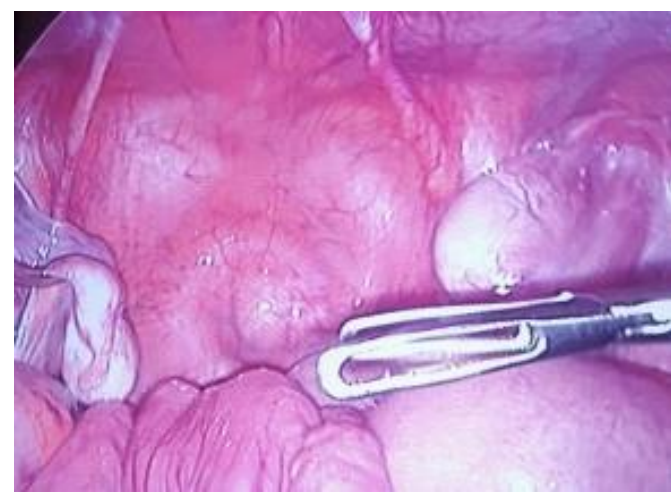

Fig.4. Right peeping and left intraabdominal testis.

All patients had single stage orchidopexy in the subdartos pouch (Fig. 5) or orchidectomy.

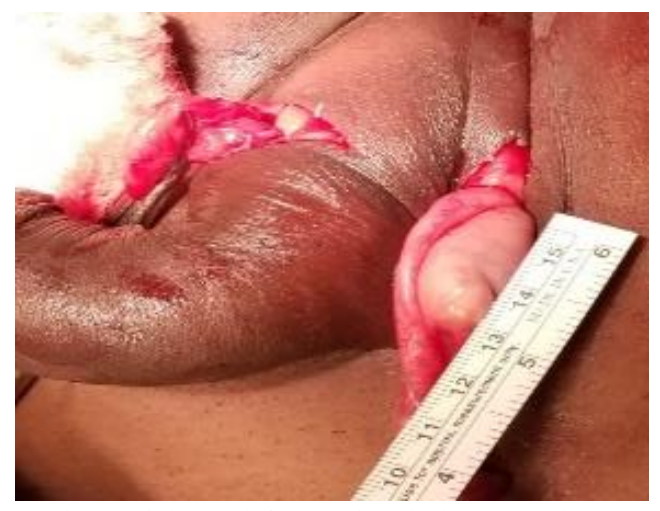

Fig. 5. Right and left testes in sub-dartos pouch.

Fig. 6 shows the skin closure after completion of the procedure in a child with previous left open bilateral orchidopexy with retraction of testis into the groin.

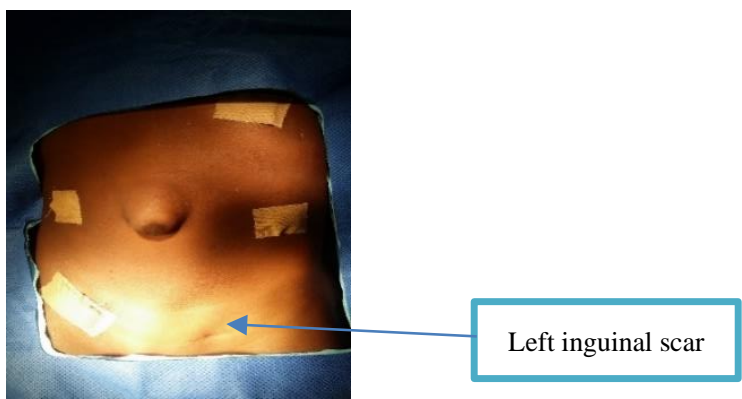

Fig. 6. Skin closure showing port sites in previous open bilateral orchidopexy.

However, men with additional varicoceles were offered laparoscopic varicocelectomy where the internal spermatic veins were dissected and divided between ligatures. Intracorporeal laparoscopic suture technique was used with vicryl $4 / 0$ suture.

\section{F. Intervention}

Laparoscopic orchidopexy, orchidectomy or varicocelectomy.

\section{G. Outcome Measures}

The presence of testis in the scrotum at 18 months of follow up. Improvement or otherwise of the postoperative semen parameters. 


\section{H. Data Analysis}

The data was entered in Microsoft Excel sheet and analysed with simple statistics of mean and percentage. The data were presented in tables and intraoperative photographs.

\section{Ethical Statement}

This study was reviewed and approved by the institution Ethical Committee of the University of Ibadan-University College Hospital from January 2015 to December 2019. The approval number is UI/EC/21/0170.

\section{RESULTS}

A total of 12 patients which comprised of $7(58 \%)$ children and $5(42 \%)$ adults with 21 undescended testes, 1 retractile testis and 3 testes in the scrotum were studied. The abdominal ultrasound identified $3(25 \%)$ intraabdominal testes. The mean laparoscopic operation time was 144.7 (90-240) minutes. The mean age of the children was 11.1 years with age range 6-17 years while the adults mean age was 35.2 years range $29-42$ years.

\section{A. Preoperative Findings}

Preoperatively there were 9 bilateral undescended testes, 3 unilateral testes, 1 retractile testis, and 2 solitary testes in the hemiscrotum. Though all the adults presented with male infertility, two of them had oligoasthenoteratozoospermia and three had azoospermia (Table I).

\begin{tabular}{ll} 
TABLE I: PREOPERATIVE EXAMINATION FINDINGS AND DIAGNOSIS \\
\hline \multicolumn{1}{c}{ Diagnosis } & Number \\
\hline Primary diagnosis & 3 \\
Unilateral undescended testis & 9 \\
Bilateral undescended testis & 2 \\
$\quad$ Descended testes & 1 \\
$\quad$ Retractile testis & 3 \\
Associated diagnosis & \\
$\quad$ Male infertility and azoospermia & 2 \\
Male infertility with & \\
oligospermia \& unilateral & \\
descended testis & \\
\hline
\end{tabular}

\section{B. Laparoscopic Operation Findings and Procedure Performed}

The operation findings at laparoscopy, the operation performed as well as the outcome of treatment (Table II).

\section{Outcome}

All the testes remained in the bottom of the scrotum at 18 months of follow up. Three of the adults had persistent azoospermia while the remaining two had improvement in the sperm count, percentage of total motility, and reduced percentage of abnormal morphology.

\section{DISCUSSION}

Undescended testis is more often seen in children than adult. This may explain the slightly higher number in this study [1]. The mean age of 35.5 years in this study is slightly higher than in other studies of 22.7 years and 29 years [6], [9]. The adults in this study presented with male infertility.

Like in other studies, abdominal ultrasound was less likely identify undescended testis compared to laparoscopy as observed in this study [5], [7].
TABLE II: INTRAOPERATIVE FINDINGS WITH OUTCOME OF TREATMENT

\begin{tabular}{|c|c|c|c|}
\hline Laparoscopic operative findings & \multicolumn{3}{|c|}{ Numbers } \\
\hline \multicolumn{4}{|l|}{ Intraabdominal testis } \\
\hline Blind ending vas \& short vessels & \multicolumn{3}{|c|}{3} \\
\hline $\begin{array}{l}\text { Normal testis volume \& cord } \\
\text { structures }\end{array}$ & \multicolumn{3}{|c|}{5} \\
\hline Intracanalicular testis & \multicolumn{3}{|c|}{5} \\
\hline Peeping testis & \multicolumn{3}{|c|}{5} \\
\hline Absent testis & \multicolumn{3}{|c|}{1} \\
\hline Dilated internal spermatic veins & \multicolumn{3}{|c|}{2} \\
\hline Operation performed, $(n)$ & \multicolumn{3}{|c|}{ Outcome at 18 months } \\
\hline $\begin{array}{l}\text { Laparoscopic unilateral } \\
\text { orchidopexy (4) }\end{array}$ & \multicolumn{3}{|c|}{$\begin{array}{l}\text { Testes remained in } \\
\text { hemiscrotum }\end{array}$} \\
\hline $\begin{array}{l}\text { Laparoscopic unilateral } \\
\text { orchidectomy (6) }\end{array}$ & \multicolumn{3}{|c|}{ Empty hypoplastic scrotum } \\
\hline $\begin{array}{l}\text { Laparoscopic bilateral orchidopexy } \\
\text { (10) }\end{array}$ & \multicolumn{3}{|c|}{ Testis remained in the scrotum } \\
\hline Open unilateral orchidopexy (1) & \multicolumn{3}{|c|}{$\begin{array}{l}\text { Testis remained in } \\
\text { hemiscrotum }\end{array}$} \\
\hline $\begin{array}{l}\text { Laparoscopic unilateral varicocelectomy } \\
\text { (2) }\end{array}$ & \multicolumn{3}{|c|}{$\begin{array}{c}\text { Improved SFA parameters at } 6 \\
\text { months }\end{array}$} \\
\hline $\begin{array}{l}\text { SFA parameter at } 6 \text { months } \\
\text { postoperative }\end{array}$ & q & $*$ & $* *$ \\
\hline $\begin{array}{l}\text { 32year old male infertility/unilateral } \\
\text { UDT \& varicocele }\end{array}$ & $90 \%$ & $76.5 \%$ & $34.5 \%$ \\
\hline $\begin{array}{l}42 \text { year old male infertility/unilateral } \\
\text { UDT \& varicocele }\end{array}$ & $94.2 \%$ & $85.7 \%$ & $37.5 \%$ \\
\hline
\end{tabular}

Most patients in our environment with undescended testis are often treated by open orchidopexy or orchidectomy probably due to lack of laparoscopic instrument or no skill to perform this procedure [12]-[14]. Even when available only few patients with undescended testis underwent laparoscopic procedures [10]. Ekwunife et al [11] reportedly performed most laparoscopic procedures for undescended testis in children except for a 29 year old man. In our study $42 \%$ of adults underwent laparoscopic orchidopexy or orchidectomy.

Several authors have reported that laparoscopy was $100 \%$ diagnostic of UDT, and the outcome of treatment is good as observed in this study [4]-[9]. The laparoscopic findings of intracanalicular, peeping, intraabdominal, absent, or vanishing testis with blind ending cord structures, and streaked testis with short cord structures in this study were reported by other authors [5], [6], [15].

In this study the mean laparoscopic operation time for orchidopexy with or without orchidectomy was 144.7 minutes which is higher than 102.7 and 129 reported by other researchers [9], [16]. This can be explained by our early experience with this procedure as well as additional unilateral varicocelectomy in adults with varicoceles. Despite this prolonged operation time the outcome is comparable with those reported in literature.

In this study, all the testes that were treated by laparoscopy remained in the bottom of the scrotum at 18 months of follow up and this is consistent with other studies [5]-[8], [15], [16].

Torricelli et al., reported that though testicular preservation was achieved in adults who had orchidopexy, although there was no fertility in those men with bilateral undescended testes. This was our observation in 3 of the adults in this study who had persistent postoperative azoospermia [9]. However, in those adults with background unilateral intra-scrotal testis and undescended testis who underwent unilateral orchidopexy with unilateral laparoscopic varicocelectomy, there was an improvement in their semen parameters.

A review by Foresta et al. [17] reported alteration in spermatogenesis in men with cryptorchidism of varying 
degree that ranged from normozoospermia to complete azoospermia as seen in the adult in this study. Testicular dysgenesis syndrome hypothesis describes the relation between genetic factors, environment disruptors, and the subsequent development of cryptorchidism, infertility, hypospadias, and testicular cancer. The longer the delay at presentation of UDT, the higher the chances of changes in the testis this may explain why some adults underwent laparoscopic orchidectomy in this study [17], [18].

\section{CONCLUSION}

Laparoscopic orchidopexy and orchidectomy should be offered to patients with undescended testis because outcome of testis remaining in the scrotum is high and additional laparoscopic varicocelectomy is beneficial in men with unilateral UDT who underwent unilateral orchidectomy.

\section{ACKNOWLEDGMENT}

We thank the nurses, anesthesia Team and the biomedical technical staffs for the support during all the theatre sessions.

\section{REFERENCES}

[1] F. J. Schneuer, A. J. A. Holland AJ, G. Pereira, S. Jamieson, C. Bower and N. Nassar. (February 2016). "Age at Surgery and outcomes of an undescended Testis," Pediatrics. [Online]. 137(2). e20152768. Available: https://doi.org/10.1542/peds.2015-2768.

[2] A. A. Okeke, and D. N. Osegbe. "Prevalence and characteristics of cryptorchidism in a Nigeria district," BJU Int, vol. 88 (9), pp. 941-945, Jan. 2021.

[3] K. Sijstermans, W. W. MHack, R. W. Meijer, and L. M. van der VoortDoedens, "The frequency of undescended testis from birth to adulthood: a review," Int J Andro. vol. 31 (1), pp. 1-11, May 2007.

[4] L. H. Braga, A. J. Lorenzo, and R. L. P. Romao. (Jul. 2017). Canadian Urological Association-Pediatric Urologists of Canada (CUA-PUC) guideline for the diagnosis, management, and follow up of cryptorchidism. Can Urol Assoc J. [Online]. 11(7). pp. E251-60. Available: http://dx.doi.org/10.5489/cuaj.4585.

[5] A. A. M. Bakr, and M. Kotb, "Laparoscopic orchidopexy: The treatment of choice for the impalpable undescended testis," JSLS., vol. 2, no. 3, pp. 259-262, Jul-Sep. 1998.

[6] R. Kucheria, A. Sahai, T. A. Sami, B. Challacombe, H. Godbole, et al, "Laparoscopic management of cryptorchidism in adults," European Urology., vol. 48, no. 3, pp. 453-457, Sep. 2005.

[7] K. Ismail, M. Ashour, M. El-Afifi, A. Hashish, N El-Dosouky, M. Nagm, and M. Hashish, "Laparoscopy in the management of impalpable testis: series of 64 Cases," World J Surg., vol. 33, no. 7, pp. 1514-1549, Jul. 2009.

[8] C. S. Desai, R. Y. Prabhu, and A. N. Supe. "Laparoscopic orchidectomy for undescended testis in adults," J Postgrad Med., vol 48, no. 1, pp. 25-26, Jan-Mar. 2002.

[9] F. C. Torricelli, M. A. Arap, R. J. Duarte, A. I. Mitre, and M. Srougi. (October 2012). Laparoscopic testicular preservation in adults with intra-abdominal cryptorchidism: is it beneficial? Advances in Urology. [Online]. 2012. 4 pp. Available: https://www.hindawi.com/journals/au/2012/329237.

[10] A. O. Talabi, A. O. Adisa, O. Adefehinti, O. A. Sowande, A. C. Etonyeaku, and O. Adejuyigbe. (Jun. 2015). Early experience with laparoscopic surgery in children in Ile-Ife, Nigeria. Afr J Paediatr Surg. [Online]. 12(1). pp. 29-32. Available:

https://www.afrjpaedsurg.org/text.asp?2015/12/1/29/150947.
[11] O. H. Ekwunife, V. I. Modekwe, J. O. Ugwu, and C. A. Ugwunne, "Early experience with laparoscopic management of nonpalpable undescended testes," Niger J Surg., vol. 23, no. 2, pp. 115-118, Oct. 2017.

[12] O. A. Sowande, A. O. Talabi, A. C. Etonyeaku, and O. Adejuyigbe, "Groin exploration for the non-palpable testes: A single center experience" Niger J Surg., vol. 21, no. 1, pp. 56-59, Mar. 2015.

[13] S. C. Ekpemo, and C. Onyearugha, "Management of undescended testis in children in Aba Nigeria," International J of Clinical Urology., vol. 3, no. 1, pp. 15-17, Jun. 2019.

[14] E. A. Ameh, and H. N. Mbibu, "Management of undescended testes in children in Zaria, Nigeria," East Afr Med J., vol. 77, no. 9, pp. 485-487, Sep. 2000.

[15] M. M. AbdElsalam, K. M. Elshimy, A. M. Elbatarny, and M. A. Elafifi, "Role of laparoscopy in management of non-palpable undescended testis in children," The Egyptian J Hospital Med., vol. 76, no. 2, pp. 3454-3459, July 2019.

[16] S. A. Dar, R. S. Bali, Y. Zahoor, A. R. Kema, R. and Bhardwaj. (Oct. 2018). Undescended testes and laparoscopy: Experience from the developing world. Adv Urol. [Online]. 2018. 5 pages. Available: https://www.hindawi.com/journals/au/2018/1620470.

[17] C. Foresta, D. Zuccarello, A. Garolla, and A. Ferlin, "Role of Hormones, Genes, and environment in human cryptorchidism" Endocrine Reviews., vol. 29, no. 5, pp. 560-580, Aug. 2008.

[18] N. E. Skakkebaek, E. Rajpert-De Meyts, and K. M. Main, "Testicular dysgenesis syndrome: an increasingly common developmental disorder with environmental aspects: Opinion," Human Reproduction., vol. 16, no. 5, pp. 972-978, May 2001.

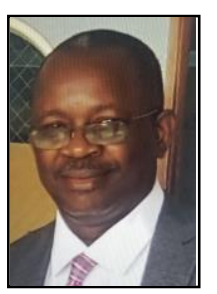

Augustine O. Takure was born 20.8.1964 in Lagos, Nigeria. Graduated with M.B.B.S at the University of Ibadan Nigeria in 1989. Underwent surgery and urology residency training from February 2001 to December 2007 at the Obafemi Awolowo University Teaching Hospital, Ile-Ife, Osun State in Nigeria. Obtained the Fellowship of West African College of Surgeons (FWACS) in 2008. Certificate of training in Renal Transplantation and Endourology July-December 2008 at the Muljibhai Patel Urological Hospital in Nadiad, Gujarat, India. Fellow of International College of Surgeon (FICS) in 2014. Major field of study: general surgery, urology, and kidney transplantation.

He worked as National Youth Service Corp (NYSC) medical offier at the university health services (1991-1992) in the University of Ibadan (UI). Medical Officer/Senior Medical Officer (1993-Jan. 2001) at UI. Junior Surgery residency training Feb. 2001- Oct. 2004) at the Obafemi Awolowo University Teaching Hospital (OATHC), Ile-Ife, Osun State in Nigeria. Senior urology residency training (Oct. 2004-Dec. 2007) at OAUTHC. Lecturer 1 (Jun. 2008-Oct. 2009) at Ambrose Alli University, Ekpoma, Edo \& Consultant Urologist at Irrua Specialist Hospital, Irrua in Edo State, Nigeria. Hospital Consultant/Associate Lecturer at University College Hospital (UCH) $\&$ College of Medicine, University of Ibadan (COMUI), Oyo State, Nigeria (Nov. 2009-Jan. 2014). Lecturer 1/Senior Lecturer at COMUI (Jan. 2014-date'2021). Honorary Consultant at UCH, Ibadan. Publications covers day case urology, prostate and kidney diseases, renal transplantation, and laparoscopy. Research interests are renal transplantation, laparoscopy, urooncology, male infertility, and reconstructive urology.

Dr. Takure. Membership in Professional societies: Nigeria Medical Association (NMA), Medical and Dental Consultant Association, Nigeria (MDCAN), General Secretary, Association of Urological Surgeons, Nigeria (NAUS), Vice President II, Transplant Association, Nigeria (TAN), Zonal Coordinator, International College of Surgeon (ICS) Nigeria National Section, Deputy National Delegate representing Nigeria in Society Internationale d'Urologie (SIU), European Association of Urology (EAU), and American Urology Association (AUA). 